\title{
USE OF ASPERGILLUS FUMIGATUS MYCELIAL ANTIGENS IN ENZYME-LINKED IMMUNOSORBENT ASSAY AND COUNTER-IMMUNOELECTROPHORESIS
}

\author{
Elaine V. Wilson and Veronica M. Hearn \\ Mycological Reference Laboratory, London School of Hygiene and Tropical Medicine, Keppel \\ Street, London WCIE $7 H T$
}

\begin{abstract}
SUmmary. Antigens obtained from the ruptured mycelium of Aspergillus fumigatus were separated on the basis of their attachment or non-attachment to Concanavalin A-linked Sepharose gel. They were analysed by double-diffusion and two-dimensional immunoelectrophoresis with rabbit antiserum and sera from patients with aspergillus-related disease. Their sensitivity was assessed in an enzyme-linked immunosorbent assay (ELISA) for immunoglobulin G. Sera which gave very low or high extinction readings on ELISA gave, in general, comparable results on counter-immunoelectrophoresis; but weak electrophoretic reactions were not closely paralleled by ELISA results. The unfractionated extract and the fraction bound by Concanavalin A-Sepharose had similar ability to detect specific IgG in sera from patients with aspergillosis.
\end{abstract}

\section{INTRODUCTION}

Mycelial extracts of Aspergillus fumigatus serve as a source of serodiagnostic antigens (Kim et al., 1978; Hearn and Mackenzie, 1979). Antigenic preparations have been obtained from a crude wall fraction by detergent extraction and from the water-soluble constituents of ruptured mycelium (Wada, 1960; Azuma et al., 1967; Tran Van Ky, Biguet and Vaucelle, 1968; Bardana et al., 1972; Hommel, Kien Truong and Bidwell, 1975).

Concanavalin A (Con A) binds to molecules that have one or both of $\alpha$-D-mannopyranosyl and $x$-D-glucopyranosyl residues, or other closely related sugars, on their surfaces. Hearn and Mackenzie (1980a) found that two antigenic fractions could be distinguished by exposure of detergent extract of aspergillus mycelium to Con A-linked Sepharose; one was not bound and the other bound by the lectin. The present report describes the use of a similar procedure on the crude water-soluble extract of aspergillus mycelium, in an attempt to produce better defined antigenic preparations, of constant quality, in amounts sufficient for use in routine diagnostic tests.

\section{MATERIALS AND METHODS}

Preparation of mycelial extract. Aspergillus fumigatus strain NCPF2109 was grown in stirred culture in neutral glucose peptone medium incubated at $30^{\circ} \mathrm{C}$ for 3 days (Proctor, 1976).

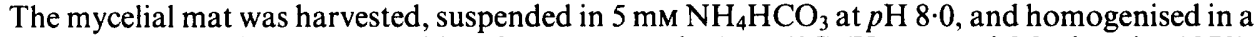
'Dynomill' cell disintegrator (Glen Creston, London) at $4^{\circ} \mathrm{C}$ (Hearn and Mackenzie, 1979). The supernate obtained after centrifugation at $2000 \mathrm{~g}$ was used as a source of water-soluble antigens. This supernate was reduced in volume by counter-dialysis against a $10 \%(\mathrm{w} / \mathrm{v})$ aqueous solution of polyethylene glycol 6000 , and referred to as WS.

Con A affinity chromatography. A column $(1.4 \times 27 \mathrm{~cm})$ of Con A-Sepharose (Pharmacia Fine Chemicals, Uppsala, Sweden) was equilibrated with $1 \mathrm{~mm}$ Tris- $\mathrm{HCl}$ buffer, $p \mathrm{H} \mathrm{7 \cdot 2,}$ containing $1 \mathrm{mM} \mathrm{CaCl}_{2}, 1 \mathrm{~mm} \mathrm{MnCl}$, and $0.25 \mathrm{M} \mathrm{NaCl}$ (Hearn and Mackenzie, 1980a). The WS extract was dialysed against this buffer and any insoluble material removed by centrifugation at $100000 \mathrm{~g}$. A portion of the supernate was applied to the column surface; the load was 
approximately $200 \mathrm{mg}$ protein, in volumes that ranged from $2-5 \mathrm{ml}$. Elution was effected in the same buffer at $4^{\circ} \mathrm{C}$ with a flow rate of $30 \mathrm{ml} / \mathrm{h}$. Fractions of $10 \mathrm{ml}$ were collected and monitored spectrophotometrically for protein content by absorption at $E_{280}$. This step resulted in the elution of material that did not bind to Con A-Sepharose. Subsequent application of $0.2 \mathrm{M}$ $\alpha$-methylmannoside (grade II, Sigma) in $1 \mathrm{~mm}$ Tris- $\mathrm{HCl}$ buffer resulted in the elution of material bound by Con A. The total elution volume was $200 \mathrm{ml}$. Individual fractions were analysed for precipitin activity by double-diffusion with an antiserum produced in rabbits. Precipitating fractions were bulked, on the basis of their affinity for Con A, as unbound fraction (UBF) and bound fraction (BF).

Chemical characterisation of antigens. The total protein of UBF, BF and WS was estimated by the method of Lowry et al. (1951), with bovine serum albumin as a standard. Total neutral sugar was determined by the method of Dubois et al. (1956), with glucose as a standard.

Double-diffusion. Column fractions were concentrated against $0 \cdot 15 \mathrm{M} \mathrm{NaCl}$ containing polyethylene glycol $10 \%(\mathrm{w} / \mathrm{v})$; a final dialysis step in $\mathrm{NaCl}$ only was routinely applied to the samples. Double-diffusion was done in agar $1 \%(\mathrm{w} / \mathrm{v})$ in borate buffer at $p \mathrm{H} 8 \cdot 2$. Antigen preparations were used at the following concentrations: column fractions at $0.4 \mathrm{mg}$ dry weight per well, and WS at $0.6 \mathrm{mg}$ dry weight per well. A rabbit antiserum to WS was used. Lines of precipitation were made more readily visible with Coomassie Brilliant Blue R (Hearn and Mackenzie, 1979).

Rabbit antisera. Antiserum to WS was prepared in New Zealand White rabbits. WS $(60 \mathrm{mg}$ dry weight $/ \mathrm{ml}$ ) was emulsified with an equal volume of Freund's incomplete adjuvant, and $1 \mathrm{ml}$ of emulsion was injected subcutaneously at weekly intervals for 5-6 weeks. Rabbit antiserum to culture-filtrate antigens of $A$. fumigatus (batch number SBL3) was a gift from $\mathrm{Dr}$ K. Holmberg, State Bacteriology Laboratory, Stockholm, Sweden.

Human sera. Sera were obtained from patients suffering from allergic bronchopulmonary aspergillosis (ABPA), aspergilloma, and other pulmonary diseases in which colonisation by aspergillus may occur. The sera had been either submitted to this laboratory, or donated by Dr J. Edwards, Sully Hospital, Wales, or Mr D. Jarvis, Public Health Laboratory Service, Leicester.

Two-dimensional immunoelectrophoresis. Tests were done on $8.2 \times 7.6 \mathrm{~cm}$ slides in a $1.2 \mathrm{~mm}$ layer of agarose gel 1\%(w/v), buffered with Tris barbitone at $p \mathrm{H} 8.6($ Hearn et al., 1980). The antigen well held $7-25 \mu \mathrm{l}$ of solution at the cathodic end of the plate. Electrophoresis at room temperature proceeded at $10 \mathrm{~V} / \mathrm{cm}$ for approximately $45 \mathrm{~min}$; in the second dimension, where the separated antigens were electrophoresed into serum, the potential difference was $1.5 \mathrm{~V} / \mathrm{cm}$, applied overnight. The sera were used at concentrations that resulted in the greatest number of peaks. Culture filtrate antiserum was used at $8 \mu \mathrm{l} / \mathrm{cm}^{2}$, aspergilloma antisera at $12 \mu \mathrm{l} / \mathrm{cm}^{2}$, and ABPA sera (concentrated five-fold) at $16 \mu \mathrm{l} / \mathrm{cm}^{2}$ (Hearn and Mackenzie, 1980b). In each test the amount of antigen preparation used contained $50 \mu \mathrm{g}$ of protein. An albumin and anti-albumin reference system was included on each plate; the albumin was placed in a well directly in front of that holding the antigen preparation.

Counter-immunoelectrophoresis (CIE). Paired wells, with edge-to-edge distances of $4 \mathrm{~mm}$, were made in the gel. Patient's antiserum $(15 \mu \mathrm{l})$ was placed in the anodal well, and antigen preparation $(5 \mu \mathrm{l})$ in the cathodal well (Mackenzie, Proctor and Philpot, 1980). After application of a constant potential difference of $4 \mathrm{~V} / \mathrm{cm}$ to the gel for approximately $1.5 \mathrm{~h}$, the slides were washed, fixed, and stained with Coomassie Blue.

ELISA for IgG antibodies. Analyses were performed in polystyrene microtitre plates (Dynatech, Plochingen, West Germany; type M129A) or polyvinylchloride plates (Cooke Engineering Co., Alexandria, Va, USA), as described by Voller, Bidwell and Bartlett (1979). WS, UBF and BF were used; the optimal concentration of each was determined by chequerboard titration with reference positive and negative sera, after overnight binding to the plastic surfaces at $p \mathrm{H} 9.6$ in $6 \mathrm{~mm}$ carbonate buffer. Serum was diluted in BSA $1 \%$ in phosphate buffered saline (PBS) containing Tween-20, before incubation for $2 \mathrm{~h}$ at room temperature in antigen-coated plates. The conjugate used was goat antihuman IgG linked to peroxidase (Miles Laboratories, Slough, England); the optimal dilution was 3000-6000, depending on the conjugate batch (Ruitenberg et al., 1976). The substrate was a freshly prepared solution of $\mathrm{O}^{\prime}$-phenylenediamine $0.01 \%(\mathrm{w} / \mathrm{v})(\mathrm{BDH}$, Poole, Dorset) in methanol citrate-phosphate buffer 7 $\mathrm{mm}$ at $p \mathrm{H} 5 \cdot 0$, containing $\mathrm{H}_{2} \mathrm{O}_{2} 0 \cdot 003 \%(\mathrm{w} / \mathrm{v})$. The enzyme reaction was stopped after $30 \mathrm{~min}$ by 
the addition of $2 \mathrm{~N}-\mathrm{H}_{2} \mathrm{SO}_{4}$ and the results were read on a Titertek Multiskan Spectrophotometer (Organon Teknika, St. Neots, Cambs) at $\mathrm{E}_{492}$.

\section{RESULTS}

\section{Affinity chromatography}

Column chromatography separated the mycelial extract into a straw-coloured fraction (UBF) that eluted with the solvent front and was protein-enriched; the material (BF) bound by Con $\mathrm{A}$ and elutable with $0.2 \mathrm{M} \alpha$-methylmannoside was colourless and carbohydrate-enriched. UBF constituted, on average, $24 \%$ of the dry weight of the material applied to the column; the corresponding figure for $\mathrm{BF}$ was $13 \%$.

Double-diffusion demonstrated several antigens in WS and UBF; BF gave two precipitin lines. All preparations were tested with rabbit antiserum.

\section{Two-dimensional immunoelectrophoresis}

The number of precipitation peaks seen varied considerably, being dependent not only on the antigenic fraction, but also on the antiserum used. WS produced a considerable number of
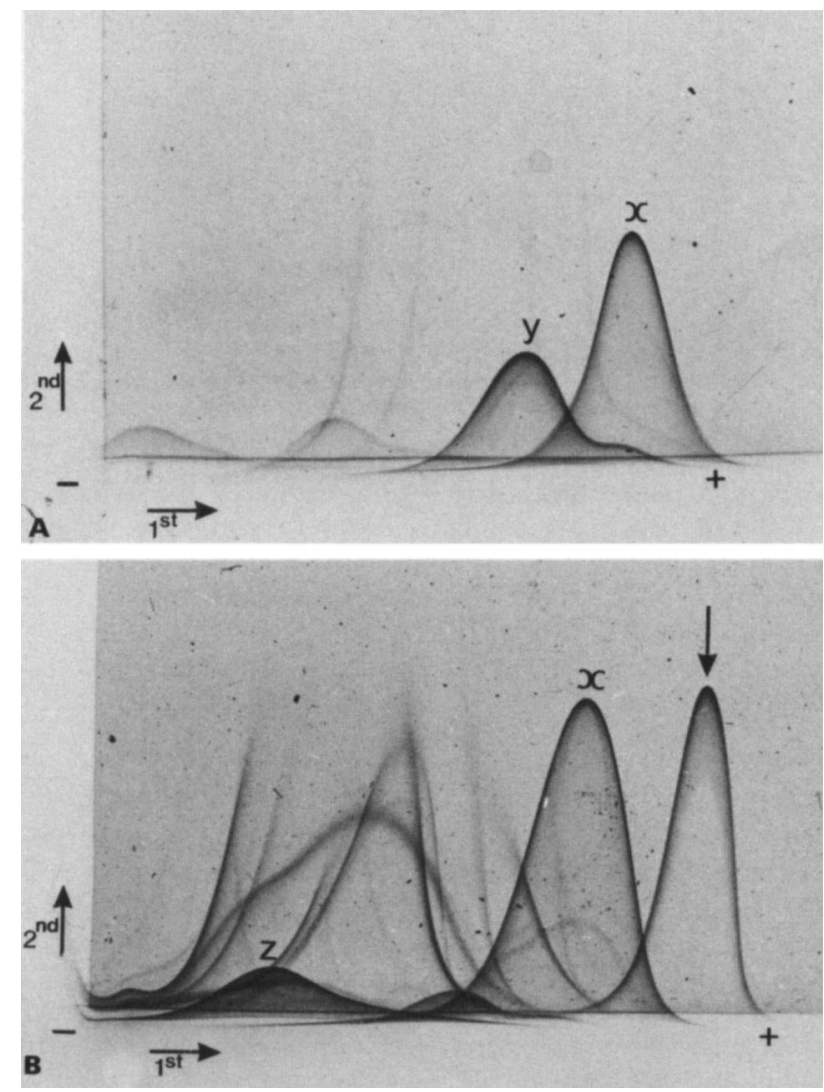

FIG. 1.-Aspergillus fumigatus antigen preparations tested in two-dimensional electrophoresis against serum from an aspergilloma patient. $a$. UBF in well next to cathode. Two components with high antigen-antibody affinity are designated peaks $\mathrm{x}$ and $\mathrm{y}$; no albumin marker was included in this slide. $b$. $\mathrm{BF}$ in well next to cathode. The anodic and cathodic components which displayed high antigen-antibody affinity are designated peaks $\mathrm{x}$ and $\mathrm{z}$; the arrow indicates the albumin-antialbumin peak. 


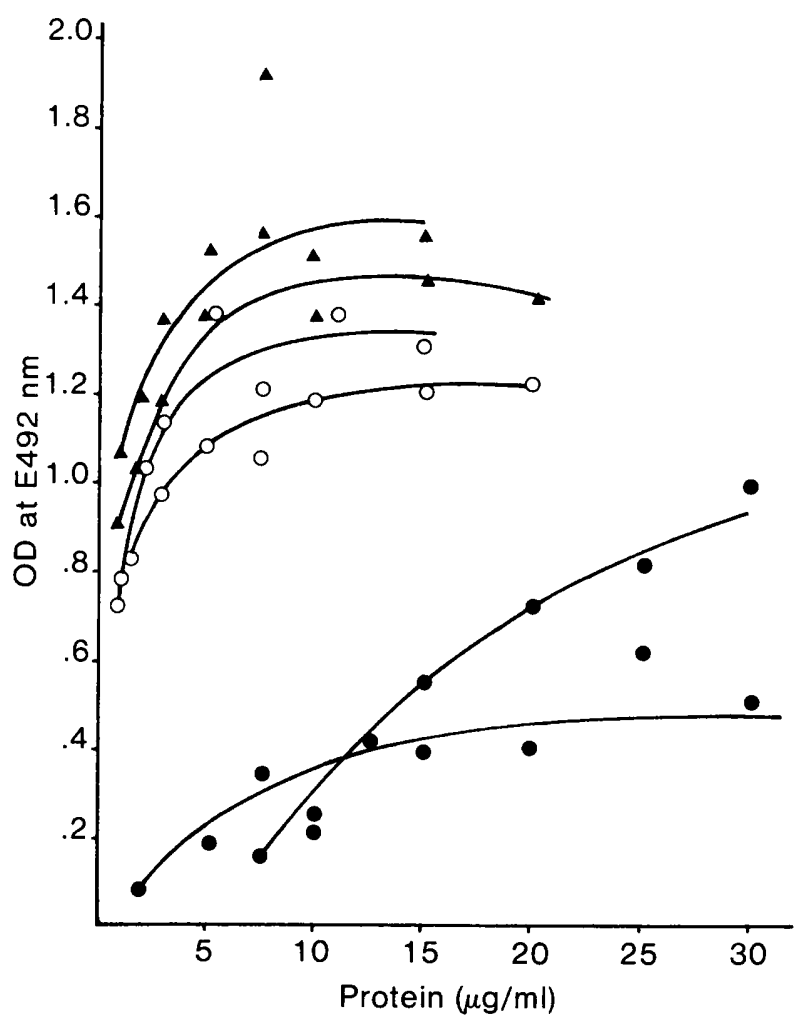

FIG. 2.-Effect of protein concentration of three $A$. fumigatus antigen preparations on intensity of colour development (OD) as measured at $\mathrm{E}_{492}$ in an ELISA system. Two different batches of each antigen preparation were tested against a reference positive human-serum pool. $\Delta-\Delta=\mathrm{BF} ; \mathrm{O}-\mathrm{O}=\mathrm{WS}$; and - UBF. The colour given by a negative human serum pool has been deducted in each case.

precipitation peaks with hyperimmune rabbit serum, but fewer with sera from aspergilloma and ABPA patients. UBF and BF gave a similar pattern of reactions. Of the three preparations, however, WS gave the greatest number of precipitation peaks with all types of antisera, and UBF the smallest. With serum from a patient with aspergilloma, UBF produced seven peaks (fig. la) and $\mathrm{BF}$ at least fourteen (fig. $\mathrm{lb}$ ). When UBF and BF were run in tandem, it became clear that they shared one major constituent (labelled " $x$ " in fig. 1) which migrated towards the anode; a number of other intensely staining peaks were shown to be peculiar to one or other fraction.

\section{Antigen and serum titration for ELISA}

Different concentrations of the three antigenic fractions gave optimal optical density (OD) readings at $\mathrm{E}_{492}$ in the ELISA system (fig. 2). Accordingly, WS was used at a strength of 5-7.5 $\mu \mathrm{g}$ protein $/ \mathrm{ml} \mathrm{(i.e.} 7-15 \mu \mathrm{g}$ dry wt $/ \mathrm{ml}$ ), UBF at $20-50 \mu \mathrm{g}$ protein $/ \mathrm{ml}$ (i.e. $30-60 \mu \mathrm{g} \mathrm{dry} \mathrm{wt} / \mathrm{ml}$ ), and $\mathrm{BF}$ at $2-5 \mu \mathrm{g}$ protein $/ \mathrm{ml}$ (i.e. $10-30 \mu \mathrm{g} \mathrm{dry} \mathrm{wt} / \mathrm{ml}$ ). On polyvinylchloride plates $\mathrm{UBF}$ was used at $20 \mu \mathrm{g}$ protein $/ \mathrm{ml}$.

To determine the optimal serum dilution, strongly, moderately, weakly, and negatively reacting reference-serum pools were tested. The dilution finally chosen was 100 ; further dilution gave no change in the readings obtained with negative sera, and with positive sera the readings were considerably reduced.

\section{Reproducibility of the ELISA}

The coefficient of variation $(\mathrm{CV})$ has been used to estimate the precision of the method 
TABLE I

Reproducibility of ELISA with different batches of Aspergillus fumigatus antigen preparations

\begin{tabular}{|c|c|c|c|c|c|}
\hline \multirow[b]{3}{*}{ Antigen } & \multicolumn{4}{|c|}{${ }^{*}$ Results, $\pm S D$, given by } & \multirow[b]{3}{*}{ Net OD } \\
\hline & \multicolumn{2}{|c|}{ positive serum } & \multicolumn{2}{|c|}{ negative serum } & \\
\hline & Mean OD & $\mathrm{CV}$ & Mean OD & $\mathrm{CV}$ & \\
\hline \multicolumn{6}{|l|}{ Single batch } \\
\hline WS & $1.506 \pm 0.09$ & 5.9 & $0.294 \pm 0.13$ & $43 \cdot 2$ & 1.212 \\
\hline & $0.626 \pm 0.25$ & 39.9 & $0 \cdot 160 \pm 0.06$ & 37.5 & 0.466 \\
\hline \multirow{2}{*}{\multicolumn{6}{|c|}{ Four batches }} \\
\hline $\begin{array}{r}\text { Four batches } \\
\text { WS }\end{array}$ & $1 \cdot 188+0.33$ & & $0.268+0.04$ & 14.9 & 0.920 \\
\hline UBF & $0.594 \pm 0.19$ & $32 \cdot 3$ & & $68 \cdot 7$ & 0.479 \\
\hline $\mathrm{BF}$ & $1.219 \pm 0.28$ & 22.8 & $0.149 \pm 0.08$ & $53 \cdot 0$ & $\begin{array}{l}1.070 \\
1.17\end{array}$ \\
\hline
\end{tabular}

Mean OD represents the average of at least four experiments. $\mathrm{CV}=$ coefficient of variation.

* Positive serum was a pool of human samples; negative serum was from a member of the laboratory staff.

(McLaren, Lillywhite and $\mathrm{Au}, 1981$ ). Interassay variation, determined by testing the same sample on different days, of less than $10 \%$ has been suggested as acceptable (Voller et al., 1979). The $\mathrm{CV}$ of one batch of each of the three antigenic preparations was determined with a positive reference-serum pool and a negative serum (table I). WS and BF gave figures within acceptable limits, but other batches were less satisfactory. The interbatch variation for WS and BF was high, and the mean results obtained when four batches of each were tested with the reference sera are shown in table $\mathrm{I}$. When allowance was made for absorption by a negative control serum, the net extinction values of WS and BF were comparable. UBF, on the other hand, gave a low mean value with a high standard deviation. No improvement was obtained when polyvinylchloride plates were substituted for the polystyrene type.

\section{Sensitivity of the ELISA}

Further experiments to test the reactivity of WS, UBF and BF were made with five pools of "high-titre" sera and an equal number of negative sera. Initially, the results were expressed as absolute OD values. On this basis (table II), there seemed little difference between WS and BF, but the mean OD figure given by UBF was definitely lower. To minimise variations in the results due to environmental factors the test serum was run in parallel with a reference positive serum, and its OD expressed in relation to an assigned OD of 1.00 for the reference serum. With this system the relative OD values of WS and BF were still comparable and did not differ significantly from the absolute values ( $p>0 \cdot 1$; table II). When the same correction factor was applied to UBF, on the other hand, values significantly higher than the absolute values were obtained $(\mathrm{p}<0 \cdot 05)$.

\section{Use of WS as an antigen preparation in ELISA and CIE}

Sera that gave negative readings on CIE had low OD values by the ELISA technique (mean $\mathrm{OD}$ at $\mathrm{E}_{492}=0 \cdot 15$, with an upper limit of $\mathrm{E}_{492}=0 \cdot 22$ ). Moreover, sera with a high titre $(\geqslant 8)$ gave a correspondingly high $\mathrm{OD}$ value $(\geqslant 0.60)$ at $\mathrm{E}_{492}$ (fig. 3 ). However, $58 \%$ of serum samples that reacted weakly (i.e., titre of 4) on CIE gave high absorption values in the ELISA. Of the sera that showed only a trace of reactivity (titre $\leqslant 2$ ) on CIE, approx. $34 \%$ gave high absorption values in the ELISA test; $10 \%$, however, gave readings below the negative cut-off point $\left(\mathrm{E}_{492}=0 \cdot 22\right)$. 
TABLE II

Reactivity of A. fumigatus antigen preparations against control sera in the ELISA, the results expressed as either absolute or relative $O D$ values

\begin{tabular}{|c|c|c|c|c|}
\hline \multirow{2}{*}{$\begin{array}{l}\text { Presentation } \\
\text { of results }\end{array}$} & \multirow{2}{*}{$\begin{array}{l}\text { Control } \\
\text { serum }\end{array}$} & \multicolumn{3}{|c|}{$\begin{array}{l}\text { Mean OD values*, } \pm S D \text {, and } \\
\text { (Net OD) given by the antigen } \\
\text { preparations }\end{array}$} \\
\hline & & WS & UBF & BF \\
\hline Absolute & Positive & $1 \cdot 286 \pm 0 \cdot 141$ & $0.451 \pm 0.126$ & $1 \cdot 132 \pm 0 \cdot 171$ \\
\hline OD values & Negative & $\begin{array}{l}0.225 \pm 0.092 \\
(1.061)\end{array}$ & $\begin{array}{l}0.115 \pm 0.046 \\
(0.336)\end{array}$ & $\begin{array}{l}0.113 \pm 0.038 \\
(1.019)\end{array}$ \\
\hline Relative $\dagger$ & Positive & $1.031 \pm 0 \cdot 165$ & $0.821 \pm 0.212$ & $0.968 \pm 0.176$ \\
\hline OD values & Negative & $\begin{array}{l}0.165 \pm 0.049 \\
(0 \cdot 866)\end{array}$ & $\begin{array}{l}0.212 \pm 0.060 \\
(0.609)\end{array}$ & $\begin{array}{l}0.086 \pm 0.029 \\
(0.882)\end{array}$ \\
\hline
\end{tabular}

* Each figure represents the average obtained from five pools of either positive or negative serum.

+ OD figures with the correction factor applied (1.00/mean OD of reference positive serum).

Use of WS, UBF, and BF in ELISA of sera from patients with aspergillus-related diseases

With WS all aspergilloma patients, $80 \%$ of ABPA patients, and $36 \%$ of asthma patients gave $\mathrm{OD}$ values greater than the highest negative reading. Of patients with bronchiectasis or bronchitis, $66.6 \%$ gave positive results (table III). Similar findings were obtained with BF, except that the lower threshold with the control negative sera gave a slightly increased number of positives in patients with bronchiectasis or bronchitis. There was no significant difference between WS and BF $(p>0 \cdot 1)$. UBF gave low results in all tests.

\section{Discussion}

The carbohydrate-rich BF proved far superior to the protein-rich UBF for detecting aspergillus antibodies by ELISA. When BF was compared with the unfractionated WS, no major difference in sensitivity was apparent. Thus, the presence of the relatively unreactive UBF components in the starting material (WS) did not reduce the activity of the starting

TABLE III

Reactivity of A. fumigatus antigens in ELISA with sera from patients with aspergillus-related disease

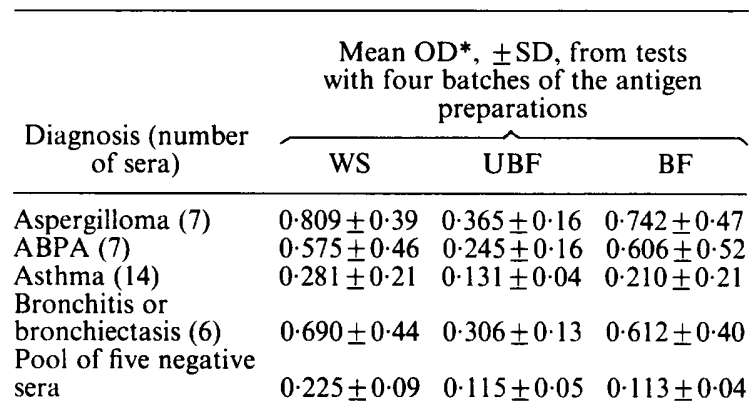

*Absolute OD values are given in order to compare the relative sensitivity of the three antigen preparations. 


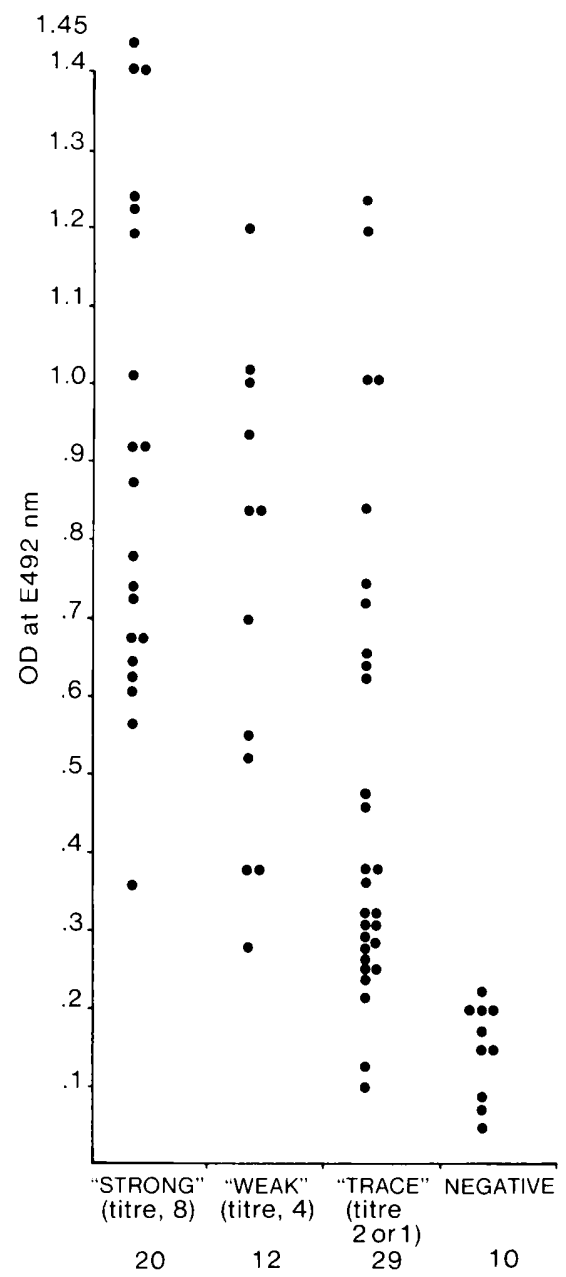

FIG. 3.- Results obtained with WS antigen preparation in a comparison of ELISA and CIE, expressed as OD values and titres, respectively. The numbers at the bottom of each column represent the number of sera in each group of four CIE categories.

material below that of BF. It is possible that the components with high antigenic activity were, by chance, selectively bound to the plastic surfaces. This suggestion is supported by the fact that a high concentration of UBF was needed to coat the plastic plates for aspergillus IgG detection.

Absolute correlation between ELISA and CIE results is not to be expected, as different reactions are concerned, viz the former measures the primary antigen-antibody interaction, but a secondary precipitation step is a prerequisite of the latter; a negative result in the CIE test does not prove the absence of antibody. However, with the conjugate used in the ELISA, IgG antibodies alone are detected whereas a precipitation test detects both IgG and IgM. The correlation between ELISA and CIE was close with strongly positive and negative sera. Some sera that gave weak or trace results on CIE gave high ELISA values, but three samples that gave a trace of reactivity on CIE gave ELISA readings lower than those of the negative controls. In the absence of further clinical data, however, it was impossible to give an opinion as to false negative and positive reactions in such sera.

In ELISA, it is essential to control factors affecting the enzyme-substrate reaction, including temperature, $p \mathrm{H}$ and substrate composition (McLaren et al., 1981). Because the enzyme reaction was stopped after a fixed period, it was thought advisable to measure OD in relation to 
the OD given by a positive reference serum. Table II shows that although this procedure was valid when an individual antigen was being assessed, it could not be used to compare antigens whose reactivity against positive reference sera varied greatly.

ELISA showed promise as a sensitive and reagent-saving test for aspergillus antibodies. It compared well with CIE and had the advantage that, with pre-sensitised plates, a result could be obtained in 6-8 h. The plastic surface appeared to select reactive antigens; this may in future render initial purification of crude extract unnecessary.

This work was supported by a grant from the Medical Research Council. We are indebted to Drs M. McLaren and J. Lillywhite for their expert advice on ELISA. We wish to thank Mr A. G. Proctor for advice and encouragement. The technical skill of Miss K. Hughes is gratefully acknowledged.

\section{REFERENCES}

Azuma, I., Kimura, H., Hirao, F., Tsubura, E. and Yamamura, Y. 1967. Skin-testing and precipitation antigens from Aspergillus fumigatus for diagnosis of aspergillosis. American Review of Respiratory Diseases, 95, 305-306.

Bardana, E. J., MCClatchy, J. K., FarR, R. S. And Minden, P. 1972. The primary interaction of antibody to components of aspergilli. I. Immunologic and chemical characteristics of a nonprecipitating antigen. Journal of Allergy and Clinical Immunology, 50, 208-221.

Dubois, M., Gilles, K. A., Hamilton, J. K., Rebers, P. A. and Smith, F. 1956. Colorimetric method for determination of sugars and related substances. Analytical Chemistry, 28, $350-356$.

HEARN, V. M. AND MaCKenZIE, D. W. R. 1979. The preparation and chemical composition of fractions from Aspergillus fumigatus wall and protoplasts possessing antigenic activity. Journal of General Microbiology, 112, 35-44.

HeARN, V. M. AND MACKENZIE, D. W. R. 1980a. The preparation and partial purification of fractions from mycelial fungi with antigenic activity. Molecular Immunology, 17, $1097-1103$.

Hearn, V. M. ANd Mackenzie, D. W. R. 1980 $b$. Mycelial antigens from two strains of Aspergillus fumigatus: an analysis by two-dimensional immunoelectrophoresis. Mykosen, 23, 549-562.

Hearn, V. M., Wilson, E. V., Proctor, A. G. and Mackenzie, D. W. R. 1980. Preparation of Aspergillus fumigatus antigens and their analysis by two-dimensional immunoelectrophoresis. Journal of Medical Microbiology, 13, 451-458.

Hommel, M., Kien Truong, T. ANd Bidwell, D. E. 1976. Technique immuno-enzymatique (ELISA) appliquée au diagnostic sérologique des candidoses et aspergilloses humaines. Résultats préliminaires. Nouvelle Presse Médicale, 5, 2789-2791.

Kim, S. J., Chaparas, S. D., Brown, T. M. And Anderson, M. C. 1978. Characterisation of antigens from Aspergillus fumigatus. II. Fractionation and electrophoretic, immunologic and biologic activity. American Review of Respiratory Diseases, 118, 553-560.

Lowry, O. H., Rosebrough, N. J., Farr, A. L. and Randall, R. J. 1951. Protein measurement with the Folin phenol reagent. Journal of Biological Chemistry, 193, $265-275$.

MacKenzie, D. W. R., Proctor, A. G. J. and Philpot, C. M. 1980. Basic serodiagnostic methods for diseases caused by fungi and actinomycetes, Public Health Laboratory Service Monograph Series No. 12. HMSO, London.

Mclaren, M. L., Lillywhite, J. E. AND AU, A. C. S. 1981. Indirect enzyme-linked immunosorbent assay (ELISA): practical aspects of standardisation and quality control. Medical Laboratory Sciences, 38, 245-251.

Proctor, A. G. 1976. Mycological Methods, In Microbiological Methods, 4th ed., edited by C. H. Collins and P. M. Lyne, Butterworth, London, p. 181.

Ruitenberg, E. J., Steerenberg, P. A., Brosi, B. J. M. And Buys, J. 1976. Reliability of the enzyme-linked immunosorbent assay (ELISA) for the serodiagnosis of Trichinella spiralis infections in conventionally raised pigs. Tijdschrift voor Diergeneeskunde, 101, 57-70. 
Tran Van Ky, P., Biguet, J. and Vaucelle, T. 1968. Étude d'une fraction antigénique d'Aspergillus fumigatus support d'une activité catalasique. Conséquence sur le diagnostic immunologique de l'aspergillose. Revue d'Immunologie et de Thérapie Antimicrobienne, 32, $37-52$.

Voller, A., Bidwell, D. E. AND Bartlett, A. 1979. The enzyme-linked immunosorbent assay (ELISA): a guide with abstracts of microplate applications. Dynatech Europe, Guernsey.

WADA, I. 1960. Immunological studies on aspergillosis. I. Immunological reactions in experimental aspergillosis by the filtrate from ground mycelia of Aspergillus fumigatus. Japanese Journal of Bacteriology, 15, 528-530. 